\section{Sounding Off}

\section{The changing health service}

\author{
P.D. Welsby and A. Welsby
}

The City Hospital, Edinburgh, EH10 5SB, UK

\section{A cause for concern}

What is the Government's agenda for the National Health Service? Their short-term intentions are explicit but have they, or the medical profession, thought through the consequences of their policies? I have four main worries.

\section{Rationing \\ 'Efficiency savings' plus 'priority setting' means rationing}

Despite some public opinion polls published in the popular press which report that $50 \%$ of the public think that health care expenditure should be unlimited, those of us who live in the real world (although we would like unlimited expenditure) realize that rationing must occur. Inflation in the NHS tends to increase faster than general inflation and, despite increases in government expenditure, in excess of that basic rate.

The question then arises 'who will do the rationing?'. Obviously not public opinion, and not the government, which is very keen on telling us what we should do by issuing mandatory instructions and charters, but baulks at telling us what we should not do - in other words what should be rationed. The closest they allow themselves to get to talk of rationing is the use of the euphemistic 'priority setting'. I suspect that rationing will not be overt reduction in effective care but rather will be enacted by insidious covert decisions not to introduce improvements, such as expensive high technology investigations or treatments.

So who will do the rationing? Surprisingly it is precisely the people who should be attempting to get the most for their individual patients - the clinicians. Whilst clinician managers are undoubt-

\footnotetext{
Correspondence: P.D. Welsby, F.R.C.P.

Dr Welsby is a Consultant at The City Hospital in Edinburgh. Amanda Welsby is a fourth year European Studies and Politics student at the University of Dundee, whose ambitions include obtaining a place on the General Management Training Scheme.

Accepted: 27 May 1993
}

edly in a better position to make the case for more resources, I fear that the response of government will not be extra cash, but rather instructions to make 'efficiency savings' (a euphemism for cuts).

When budgets are cut, or do not keep pace with NHS inflation or other increases in demand, then clinicians who have to remain within budget will soon have to reduce services to patients. These clinicians will be perceived to be, quite literally, in business rather than in a caring profession.

Aneurin Bevan's greatest achievement was the creation of a national health service which was based on the principle of collective responsibility by the state for a genuinely universal and comprehensive range of services with equal access for all citizens. I believe that, $\mathbf{4 5}$ years later, governments should still take a central role in deciding policy with regard to certain illnesses and investigations, and should decide what health care facilities should be available to all and which should be limited. This is too important to be left with local or regional bodies and market forces.

\section{Training grades will become tradespeople}

The junior grades, after decades of ineffective action by seniors, are achieving civilised working hours. Unfortunately this has been allowed to happen without the simple, not unreasonable, demand that fewer hours worked by individual doctors should be matched by an equivalent increase in the number of doctors (all it requires is a government realization that the UK is far behind the rest of Europe in the proportion of the gross national product spent on health care and in the number of doctors employed per head of population).

The team care approach of hospital clinicians, which has a proven track record, is being dismantled when it deserves continuing improvement. To achieve the reduction in working hours, crosscover is necessary and rigid rotas have to be introduced. In effect the juniors are having imposed upon them knocking-on and knocking-off trade rotas. Cross-cover between different teams is fine 
for large numbers of patients with brief duration illnesses such as casualty or routine minor surgery. It is a potential disaster for large numbers of patients with dynamic illness of medium to longterm duration such as on-take medicine or surgery where continuity of care is important. Patients with dynamic illnesses will now have to get used to seeing a doctor who they have not seen before and may not seen again. Such alterations to the team care approach, which uses the same restrictions of working hours across all hospital specialties, shows gross ignorance of differing work practices in different specialties.

\section{Clinicians in management will be perceived to be in business}

A few years ago managers were telling clinicians that management was a special skill. It now appears that attendance at a few management courses is all that is required. We have all listened to itinerant evangelist clinicians in management explaining the why and how of management, how easy it is, and that it can be fun. No one seems to ask whether the clinicians should become managers. The result is that many bright-eyed workaholic clinicians are rushing into the role of managers without taking a broader view. Part of the broader view should be the realization that they will have to ration the provision of medical care delivered to their patients.

I do not object to rationing, but I do have strong misgivings when rationing is to be done by clinicians. Clinicians should devote themselves to eliminating ineffective care. Clinicians with budgets and managerial responsibility are now becoming arbiters and instruments of health care provision, and contradictory policies will be implemented. This is not what Bevan intended at all. An example is the recent British controversy between different cardiac surgery units as to whether cardiac surgery should be withheld from those who continue to smoke. In any event such clinicians with budgets cannot look their patients in the eye and say 'I am doing the best I can for you'. All they can say is that 'I am doing the best I can for my patients'.

Regrettably, clinicians have been recruited to management and have switched, to a greater or lesser extent, their allegiance from individual patient care to management of groups of patients. This is a transmogrification of the doctor-patient relationship and patients are thereby losing the independence of their greatest advocates. To my immense surprise, no one seems to have noticed! Perhaps I am old fashioned in my belief that clinicians should look after individuals to the best of their ability.

Ideally, in a national health service, doctors should care for their patients and attempt to treat them to the best of their ability irrelevant of cost. Give doctors budgets, and cost considerations will alter what the clinician would wish to provide for individual patients and the doctor-patient relationship has been fundamentally changed. NHS patients (and all the public are potential NHS patients) ought to be made aware of this and, before it is too late, they should decide whether they wish to be treated by doctors, or alliances of medically qualified business and trade people.

Obviously clinicians cannot be allowed to offer care irrelevant of the cost. Managers, if they deserve this title, and not clinicians, should decide policies for care of groups of people after taking advice from clinicians. Clinicians and managers have different roles. Clinicians should want to do their best for individual patients whereas managers have a more difficult task as they have to organize clinical services to deliver the greatest good for the greatest number. These two roles are incompatible and should be in conflict. Conflicting stances can be overt and constructive - indeed acceptance of opposition is at the heart of parliamentary democracy.

\section{The consultant workload will increase}

The consultants are now having to devote more time to budgeting, management, constructing rotas and attending meetings. However, many consultants wish to maximize their patient contact and minimize the business aspects. This should be possible given good management and, importantly, provided that we realize that we should be happy to be managed. In private hospitals this appears to have been achieved.

The consultants have accepted all the new changes without significant objection. As we ascended the career ladder we were progressively selected to treat each new demand as a challenge: any hint that one was lazy would have brought our progressive selection to a halt. Thus, as a group we are workaholics and will do almost anything that we are asked without questioning as much as we should. The result is that our workload will increase and our power will be diminished. We are thus extremely vulnerable.

Are my views paranoid or reactionary? No, although admittedly they may be partially selfinterested. If I were in government I would try to do precisely the same! But I hope I would not be allowed to succeed.

\section{Not a cause for concern}

As I am hoping to pursue a career in hospital management, my father asked for my comments on 
his article. We obviously see the same situations from different perspectives.

I do not think governments can make locally relevant policy decisions. Successive Conservative governments have centralized control from localities to Westminster. Yet the regions of the United Kingdom are not the same: each region has different characteristics and health care needs that require decisions to be made locally. If local government no longer has this competence, such decisions must be made by managers and doctors.

I have not heard that the training grades are complaining about their reduced hours of work. Continuity of care is important but is it as important as obtaining the best care available? It may be that the two cannot be had together given the ridiculously long hours worked by training grades. Given that finance for significant increases in the numbers of doctors is unlikely, which is better continuity of care given by tired overworked doctors or less continuity given by more alert doctors? I know which I would prefer.

I agree that clinicians and managers have different roles, but they must overlap. I am worried about the concept of acceptable conflict between clinicians and managers. Conflict inevitably breeds discontent even if it is constructive and to start discussions assuming conflict risks jeopardising clinician-manager relations. The analogy between clinician-manager constructive conflict and parliamentary democracy is a poor one for two reasons. Firstly the functioning of parliament clearly involves conflict because decisions can still be made as the UK uses the simple majority voting system (using three line whips if necessary). Secondly, many decisions of parliament do not affect the MPs that make them.

I agree that clinicians have to realize that they should be happy to be managed (I expect many hospital managers would agree too). This will not become universal unless all medical students are educated regarding management and have risen to responsible positions.

The situation at present does seem divisive. Some clinicians wish to devote themselves exclusively to patient care and be managed whereas others also revel in management roles. The problem occurs when clinicians do not wish to be managers or to be managed.

Inevitably doctors and managers have to make decisions between them, using budgets allocated by central government. Hospital income generation schemes, independent of government, should add cash to hospital budgets and help ease allocationary nightmares. Self-determination is surely better than direct rule from Westminster. 